\title{
Extending assistive devices: using the existing interface versus using a new interface
}

\author{
Nirit Yuviler-Gavish ${ }^{1}$ (D) Eitan Kribu ${ }^{1} \cdot$ Avi Weiss $^{2} \cdot$ Uri Ben-Hanan $^{2}$
}

Received: 9 August 2021 / Accepted: 2 November 2021

Published online: 17 November 2021

(c) The Author(s) 2021 OPEN

\begin{abstract}
The current research examined whether or not the interface of an extender attached to an assistive device should be identical to the interface of the assistive device. Given the profile of assistive devices such as wheelchairs and the need to extend them in special cases such when maneuvering over rough terrain or obstacles such as stairs and steep inclines, the interface design of these extenders (attached to existing assistive devices) should be evaluated. We have simulated a carrying platform for a wheelchair that is larger than the user's regular wheelchair. We have examined whether participants used to handling their wheelchair, when asked to operate the carrying platform, handle the latter's interface better or worse than their wheelchair's interface. Participants (61) were assigned to one of two between-participants groups. Both groups were trained to navigate a wheelchair using the wheelchair's interface and then operated the carrying platform. The Familiar Interface group navigated the carrying platform using the wheelchair's interface, and the New Interface group navigated it with a new interface. The results demonstrated that the Familiar Interface group took longer to perform the task and collided more often with obstacles, compared to the New Interface group. The greater number of collisions can be linked directly to an erroneous mental model of the carrying platform's size. The insights we reach can be linked to both extenders attached to an assistive device and other technological extenders.
\end{abstract}

Keywords Mental models · Assistive device - Extender · Transfer of training · System design · Physical disabilities

\section{Introduction}

Numerous and diverse assistive devices for individuals with disabilities exist and are basically defined as pieces of equipment or systems that are used to increase, maintain or improve functional capabilities of individuals with disabilities [21]. Assistive devices can include, for example, a raised toilet, a garage door opener, wheelchairs, walkers, prosthetic arms or legs, exoskeletons (wearable robotic systems that are used for augmenting human strength capabilities $[22,28]$ ), assistive technologies for adaptive learning environments ([26], etc.). Assistive devices are needed by special populations such as the elderly people as well [30]. Some devices are used rarely or only on specific occasions, while wome are tightly connected to the individual's daily life and extend human strength and/or their physiological capabilities while in physical contact with the user $[15,16]$.

In the current paper, we address the situations in which such assistive devices need to be extended, and we focus on the design of the extenders attached to these assistive devices. For the purposes of our research, we have focused on wheelchairs. Wheelchairs have maneuverability problems traversing rough terrain such as sandy, rocky or snowy ground or obstacles, e.g., stairs or even steep inclines [18]. To overcome such challenges, Weiss

Nirit Yuviler-Gavish, nirit@braude.ac.il | 'Department of Industrial Engineering and Management, ORT Braude College, P.O. Box 78, 216100 Karmiel, Israel. ${ }^{2}$ Department of Mechanical Engineering, ORT Braude College, Karmiel, Israel.

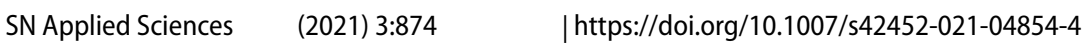


et al. [29] have designed a system that carries the user's regular wheelchair over obstacles while seated in their original wheelchair. In other words, the system is an extender attached to the wheelchair-an assistive device that extends the wheelchair's capabilities enabling both it and the user to traverse rough terrain. The carrier platform is a robotic unit that is capable of performing the desired maneuver. The translation platform is mounted on the carrier platform. The former includes two sets of rollers, one per wheelchair wheel, a set of sensors and a harness to secure the wheelchair in place. The user boards the system using a small ramp (that may be part of the carrier robot or an external piece found at the location) and is secured to the carrier by an attendant. The user remains in the original wheelchair. The wheelchair user, while on the translation platform, which rests on the carrier platform, moves the wheelchair as if it were on regular terrain. The motion of the wheels is measured by the dynamic mimicking or mirroring platform. The wheels are not prevented from moving; rather, their motion is measured and translated into commands to the carrier platform, which is what surmounts the obstacle. Figure 1 shows a basic illustration of the carrier platform with the wheelchair mounted on it.

When designing such "extensions" to activate assistive devices, an important consideration is whether the

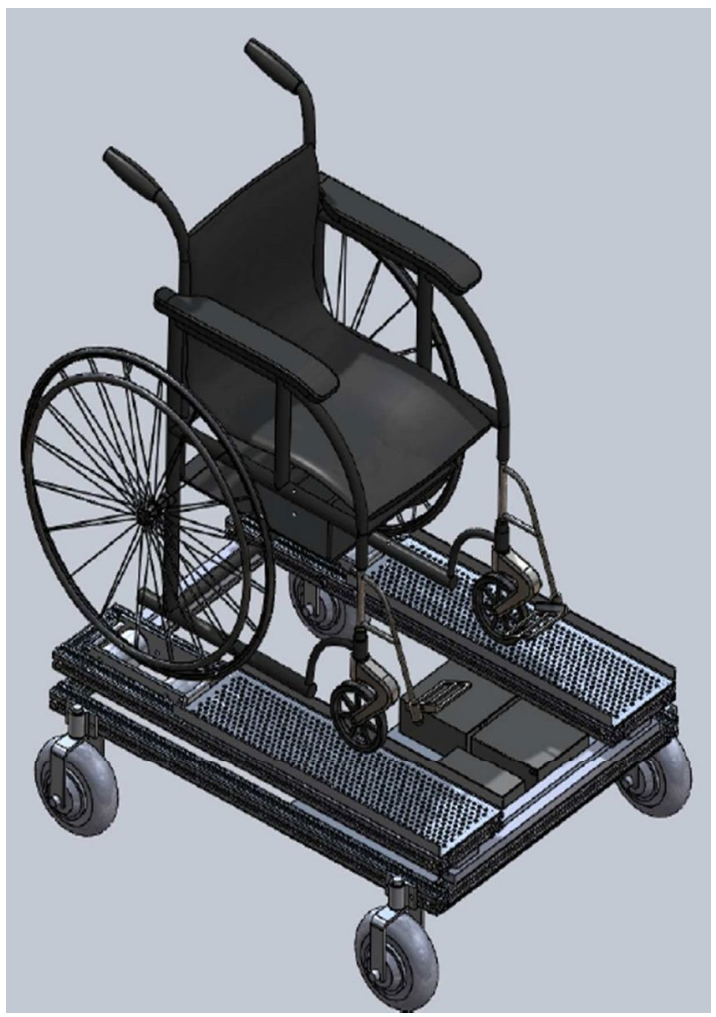

Fig. 1 A basic illustration of the carrier platform with the wheelchair mounted on it

SN Applied Sciences

APRINGER NATURE journa interface should replicate the familiar interface of the assistive device. Using the above-mentioned example of Weiss et al. an extension [29], should the researchers develop a new navigation system for their terrain maneuvering wheelchair carrier or should their new carrier use a system with which users would already be familiar? We have conducted a deep and broad survey of the literature about transfer of learning and mental models to answer this question.

Transfer of learning refers to the process of applying knowledge, skills, and abilities learned in one context to a different setting [2]. For example, adaptation to different and new e-learning systems is affected by transfer of learning [20]. Transfer of learning can be either positive or negative [5]. In positive transfer, the learner correctly applies the knowledge, skills, and abilities learned in one setting to another, while in negative transfer, knowledge and skills from a previous experience impede proper performance in a different setting. One example of negative transfer is the mistakes made by users when upgrading from a typewriter to a text editor [3]. Another example could be the difficulties that a typist adept at using a QWERTY keyboard would have when learning to use a non-QWERTY keyboard such as a DVORAK keyboard [9].

The argument for using the familiar interface of the assistive device for the extender is that the former will support positive transfer of learning for using the latter system. The user will subconsciously already know how to operate the extender attached to the assistive device, e.g., the wheelchair carrying platform, because they know how to operate the assistive device, e.g., the wheelchair itself. In contrast, the argument against using the assistive device's interface is that it might lead to negative transfer of learning and impair performance because of a misleading mental model.

The term mental model refers to the user's understanding of how a particular device works, its internal structure, the related processes, etc. $[8,14,25]$. It is apparent that this understanding does not have to be accurate or comprehensive to support successful operation of a device. For example, the user should not have to be familiar with the technological aspects of their smartphone to be able to operate it correctly. Most mental models are simpler and less complicated than realworld phenomena [24]. In addition, they may contain inaccurate information [24] and "are frequently deficient in a number of ways perhaps including contradictory, erroneous, and unnecessary concepts" ([25], p. 14). The most important attribute of the user's mental model of a device is its usefulness. Kieras and Bovair [17] have suggested that a mental model is useful when it supports inferences about exact and specific control actions. 
The risk of using the assistive device's interface to operate its extender is that the user's mental model will be based on the assistive device's characteristics and will not take into account the different qualities of its new extender, thus leading to wrong or non-optimal control actions. For example, an extender attached to a prosthesis limb might enable the user to reach farther, but if the user's mental model is based on the reaching limitation of the prosthesis limb, they will not exploit this advantage.

Our research in the current study sought to determine whether the interface of the extender attached to an assistive device should be identical to the interface of the latter or should be a new one. The research hypothesis is that while using an identical interface will have operational benefits in terms of positive transfer of learning, in some cases, a mistaken mental model that is drawn from the assistive device to the new attached extender will lead to negative transfer of learning.

To test our hypothesis, we have simulated a case in which negative transfer of learning could take place. Similar efforts to model a system for evaluating issues in human factors engineering were made by Aromaa and Väänänen [1], and Peruzzini et al. [27] in the context of a workstation. Our scenario uses the wheelchair carrying platform described in Weiss et al. [29] study. One characteristic of the carrying platform, which features strongly in our scenario, is that it is larger than the wheelchair. Using a computer simulation, our study participants were trained to navigate using a wheelchair, and then were asked to navigate using a carrying platform that was wider and longer than the wheelchair. Participants were divided randomly into two groups. One used the wheelchair's interface, with which they had trained, to navigate the carrying platform, while the second group used a new interface to control the carrier. The performance results of the two groups were compared. We have hypothesized that the performance of the group that used the wheelchair's interface will be worse compared to the performance of the other group, because the former's mental model will not take into consideration the carrying platform's size.

\section{Method}

\subsection{Design}

The study compared two between-participants groups, the Familiar Interface group and the New Interface group. Both groups were trained to navigate a wheelchair using the wheelchair's interface and then were asked to navigate the carrying platform. The Familiar Interface group navigated the carrying platform using the wheelchair's interface, and the New Interface group navigated it with a new interface. Both interfaces were designed to reflect real-world interfaces.

\subsection{Participants}

The participants were 61 undergraduate students (21 males, 17 females) from ORT Braude College, Israel. Thirty participants ( 21 males, 9 females) were randomly assigned to the Familiar Interface group, and 31 participants ( 23 males, 8 females) were randomly assigned to the New Interface group. Participants' average age was 24.7, ranging from 19 to 29. All participants had normal or corrected-to-normal visual acuity. None of them used a wheelchair regularly, but nine participants (four in the Familiar Interface group and five in the New Interface group) had past experience operating a wheelchair device. Their other technical skills in device controlling were not evaluated since using the simulation did not require any technical skills. All participants received a fixed payment of NIS 80 (about USD 23) for participating.

\subsection{Experimental task}

The participants used a computer simulation, which was built using Wix and operated via the web on computer desktops with $1024 \times 768$ resolution. Their task was to navigate as quickly as possible to four different destinations. Figure 2 demonstrates the simulation, participants' initial location (marked by an arrow) and the four destinations (displayed by a picture). Obstacles were located along the track (marked in blue circles), and participants could not navigate through them.

The study comprised two stages: a training stage and a transfer stage. In the training stage, the two groups navigated using a wheelchair, which was simulated by a yellow $1 \times 1$ square. In the transfer stage, the groups navigated using a carrying platform, which was simulated by a yellow $2 \times 2$ square. In both stages their goal was to navigate to the four destinations. Figure 3 illustrates the two systems.

The wheelchair was moved using four arrows, as shown in Fig. 4. The participant operated the wheelchair's interface using buttons on the computer mouse (controller). The operating instructions were designed to simulate those of a real wheelchair, as shown in Fig. 4.

The new interface designed to simulate the operation of the carrying platform also used four arrows, as shown in Fig. 5 and was also operated using the mouse (controller) buttons. Its operating instructions, however, were simpler than those of the wheelchair's interface as shown in Fig. 5. 
Fig. 2 A screenshot from the simulation displaying the initial location, the destinations and the obstacles

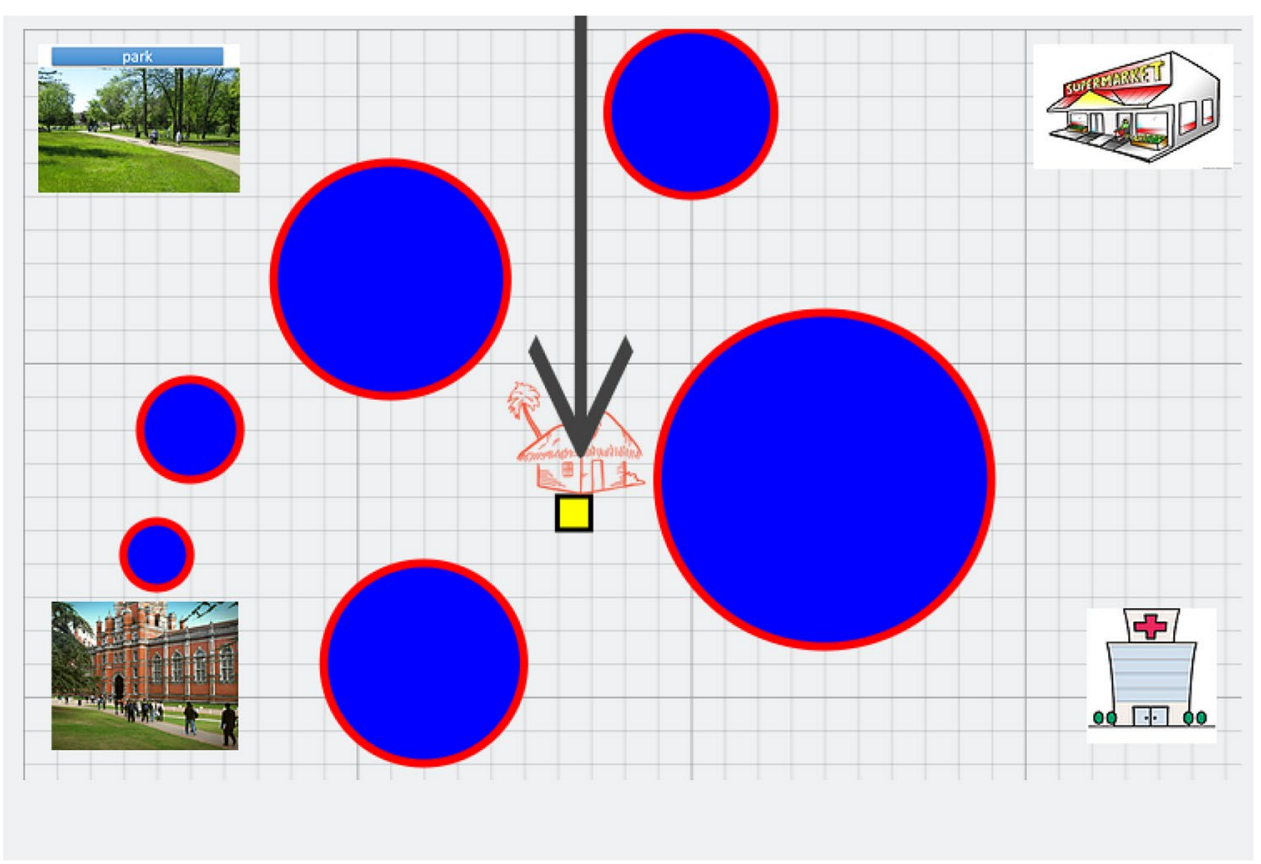

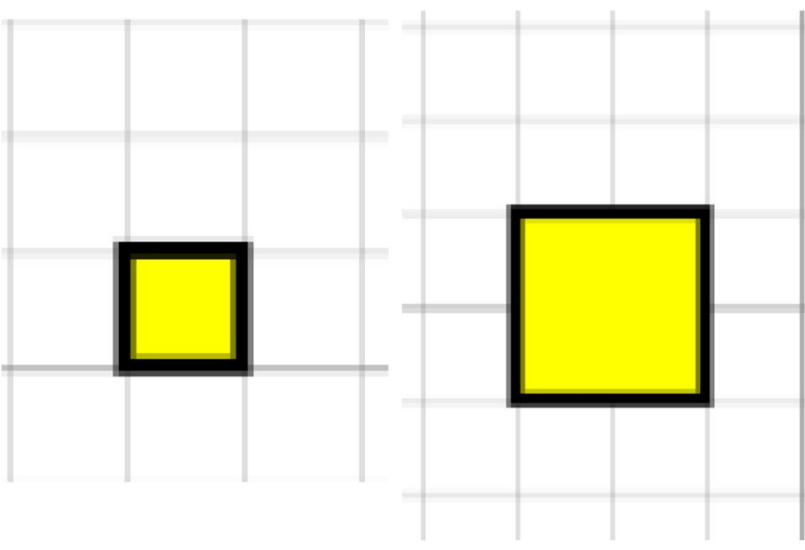

Fig. 3 Simulation of the wheelchair (left) and the carrying platform (right)

\subsection{Procedure}

This research complied with the American Psychological Association Code of Ethics and was approved by the Institutional Review Board at ORT Braude College. Informed consent was obtained from each participant.

The experiment took place in a computer laboratory at ORT Braude College, Israel. The participants met in groups of about 10, but each participant worked individually at a desktop computer. Each group was assigned randomly to one experimental condition. The experiment lasted about one hour.

After gathering in the laboratory, participants signed a consent form and completed a personal details questionnaire. Once participants were assigned to a group, the experimenter described the experimental task, and explained that it consisted of two stages. The wheelchair operating instructions were then explained, and participants were told that they could read them again at any time by pressing the Instructions button. Next, participants performed a short task (online) to ensure that they understood the wheelchair operation (interface). Following this, they entered the training stage-navigation to the four destinations with the wheelchair. Figure 6 presents a screenshot from the simulation that shows the process of navigating over/around the obstacles from the viewer's perspective.

After completing the training stage, the participants started the transfer stage, in which they navigated the carrying platform to the four specified destinations. For the Familiar Interface group, the wheelchair interface operating instructions were reexplained, and participants again performed a short experimental task to ensure that they understood how to operate the carrying platform (interface). For the New Interface group, the operating instructions of the new interface were explained, followed by a short experimental task. Afterward, both groups navigated to the four destinations, each using its own interface. 
Fig. 4 Wheelchair's interface and operating instructions. The number near the arrows indicates the number of mouse clicks made by the participant
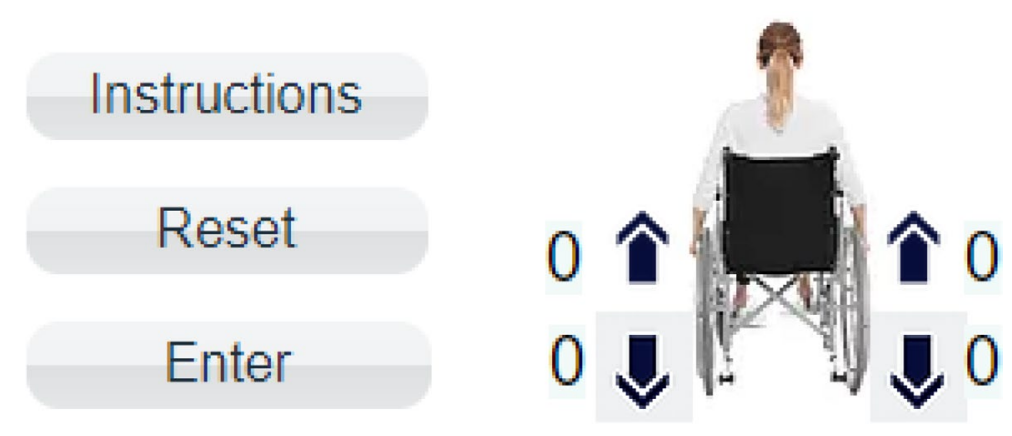

Move forward: Click once on each of the two upper arrows, and then click Enter.

Move backward: Click once on each of the lower arrows, and then click Enter.

Move right: Click twice on the upper left arrow, click once on the lower right arrow, and click Enter.

Move left: Click twice on the upper right arrow, click once on the lower left arrow, and then click Enter.

Moving diagonally is not allowed.

You can only move one step (one square) each time.

A command can be deleted before clicking on Enter by clicking on Reset.

If the square to which the wheelchair should progress is occupied or partly occupied (by the blue obstacles), you will not be able to progress, and you will get a comment: "You have encountered an obstacle! Try again."

\section{Results}

In each stage, training and transfer, four dependent performance measurements were evaluated: total performance time for navigating to the destinations, total number of steps during the navigation, total number of operation errors (e.g., clicking Enter after clicking an illegal combination of arrows, for example, 3 clicks on the upper arrow), and total number of times the wheelchair or the carrying platform collided into an obstacle-since navigating through the obstacles was not possible, colliding into the obstacle means touching it. At each stage, four independent sample, equal variances assumed, $t$ tests were performed, one for each performance measure. The grouping variable was the group: Familiar Interface versus New Interface group.

\subsection{Training stage}

For the training stage, as expected, all performance parameter measurements were found to agree, i.e., no 
Fig. 5 New interface and operating instructions. The number near the arrows indicates the number of mouse clicks made by the participant

\section{Instructions}

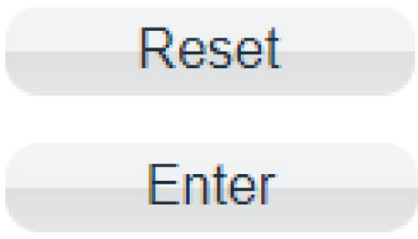

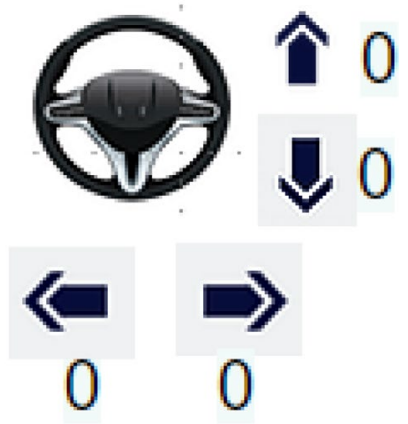

Move forward: Click once on the upper arrow, and then click Enter.

Move backward: Click once on the lower arrow, and then click Enter.

Move right: Click once on the right arrow, and then click Enter.

Move left: Click once on the left arrow, and then click Enter.

Moving diagonally is not allowed.

You can only move one step (one square) each time.

A command can be deleted before clicking on Enter by clicking on Reset.

If the square to which the wheelchair should progress is occupied or partly occupied (by the blue obstacles), you will not be able to progress, and you will get a comment: "You have encountered an obstacle! Try again."

significant difference was found between the two groups: total performance time (for the Familiar Interface group: $M=404.7 \mathrm{~s}, \mathrm{SD}=172.3$; for the New Interface group: $M=376.7 \mathrm{~s}, \mathrm{SD}=133.9, t(59)=-0.71, p=0.48)$, total number of steps (for the Familiar Interface group: $M=100.4$, $S D=18.2$; for the New Interface group: $M=103.5, S D=19.2$, $t(59)=0.63, p=0.53$ ), total number of operation errors (for the Familiar interface group: $M=6.4, S D=10.7$; for the New Interface group: $M=4.7, \mathrm{SD}=4.2, t(59)=-0.85, p=0.40$ ), and total number of collisions (for the Familiar interface group: $M=1.9, \mathrm{SD}=1.9$; for the New Interface group: $M=2.0, \mathrm{SD}=2.1, t(59)=0.20, p=0.84)$.

\subsection{Transfer stage}

In the transfer stage, the total performance time was significantly longer for the Familiar Interface group $(M=443.5 \mathrm{~s}, \mathrm{SD}=139.6)$ compared to the New Interface group $(M=318.6 s, S D=74.1 ; t(59)=-4.4, p>0.001)$, as shown in Fig. 7. In addition, the total number of collisions was also significantly higher for the Familiar Interface group $(M=2.2, S D=2.2)$ compared to the New Interface group $(M=1.2, \mathrm{SD}=1.6 ; t(59)=-2.16, p=0.035)$, as shown in Fig. 8. No significant difference was found between the parameter measurement values for both 
Fig. 6 A screenshot from the simulation when navigating to a destination
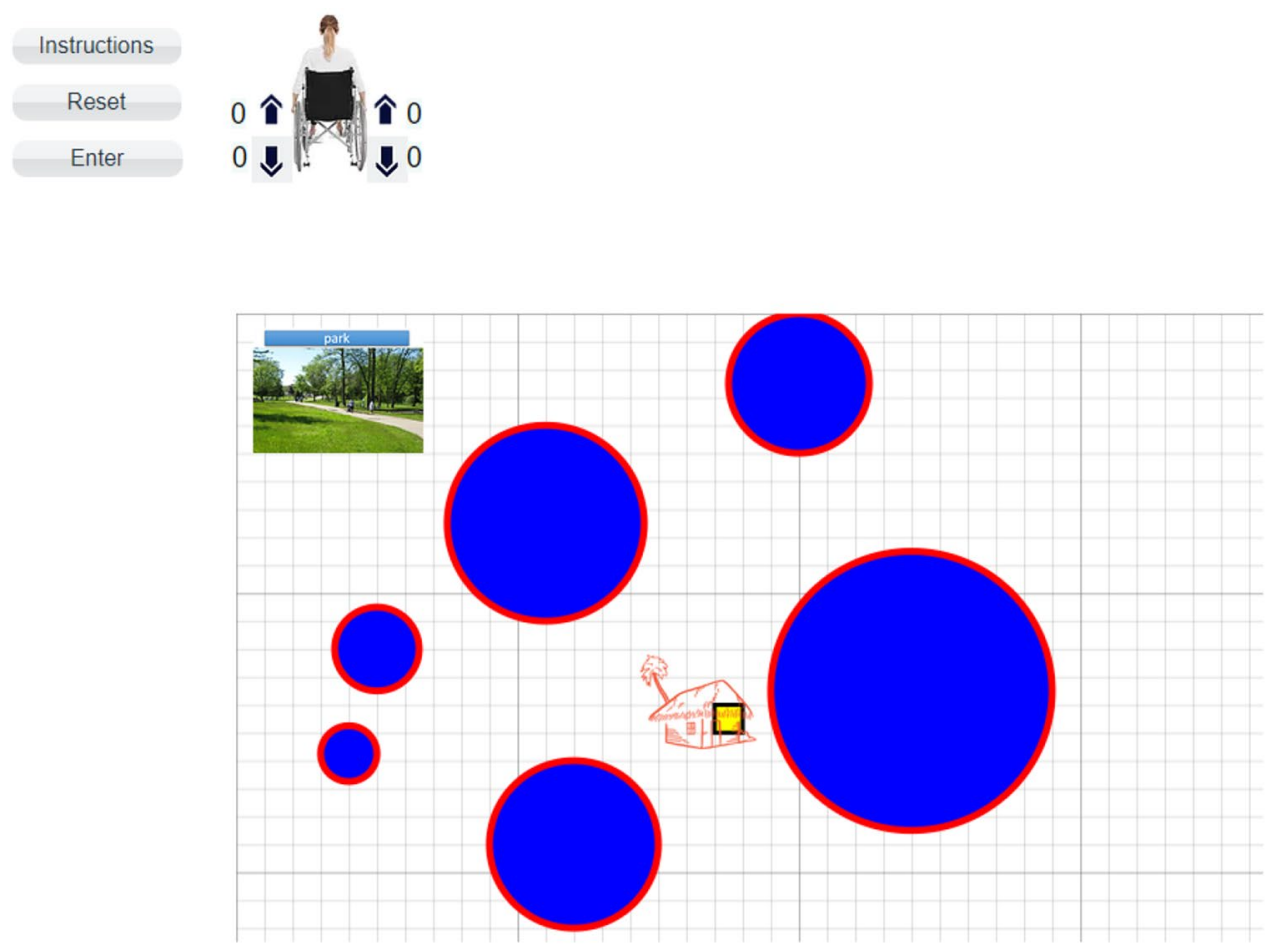

groups: total number of steps (for the Familiar Interface group: $M=123.7, S D=11.8$; for the New Interface group: $M=121.4, \mathrm{SD}=11.4, t(59)=-0.76, p=0.45)$, and total number of operation errors (for the Familiar Interface group: $M=2.2, \mathrm{SD}=3.0$; for the New Interface group: $M=2.1$, $\mathrm{SD}=2.5, t(59)=-0.19, p=0.85)$.

\section{Discussion}

Given the proliferation of assistive devices [15, 16] such as wheelchairs and the need to extend them for special cases such as maneuverability over rough terrain or over obstacles such as stairs and steep inclines [18], the current research has examined whether the interface of the extender attached to an assistive device should be identical to the interface of the assistive device or should be a new separate design with its own features. We have simulated operating a carrying platform for a wheelchair that is larger than the wheelchair and have examined whether participants trained in operating the wheelchair and later asked to operate the carrying platform will perform better or worse using the wheelchair's interface compared to using the carrying platform's interface.

The results supported our hypothesis. Participants who operated the carrying platform with the wheelchair's interface took longer to perform the task, and collided with more obstacles, compared to participants who operated it with a new interface more suitable to the carrying platform. We note that the wheelchair's interface, simulating that of a real-world wheelchair interface, was harder to manipulate than the carrying platform's interface. Hence, the difference in performance time might be due to this difference in operation difficulty, and not necessarily a consequence of negative transfer of learning [5]. The greater number of collisions, however, can be linked directly to the erroneous mental model $[8,14,25]$ of the carrying platform's size: the participants perceived the platform as smaller than its real size because of the persistence of their mental model of the wheelchair's size and hence collided more often with the obstacles.

Taking a wheelchair as an example of an assistive device is interesting since wheelchair users are significantly affected by the capabilities of their wheelchair, which impact their self-image and personal identity. They perceive the wheelchair both as an extender that makes their lives easier and, on the other hand, as a device that prevents them from doing things they would like to do [23].

In a similar way, a cyborg can be referred to as a human with an extender attached. The term "cyborg""cybernetic organism" — was coined by Manfred Clynes and Nathan Kline [6] to describe a human with enhanced abilities as a result of the integration of some artificial component or technology that relies on some sort of feedback [4]. A cyborg is not necessarily an individual with disabilities who uses assistive devices, but can be any individual. 


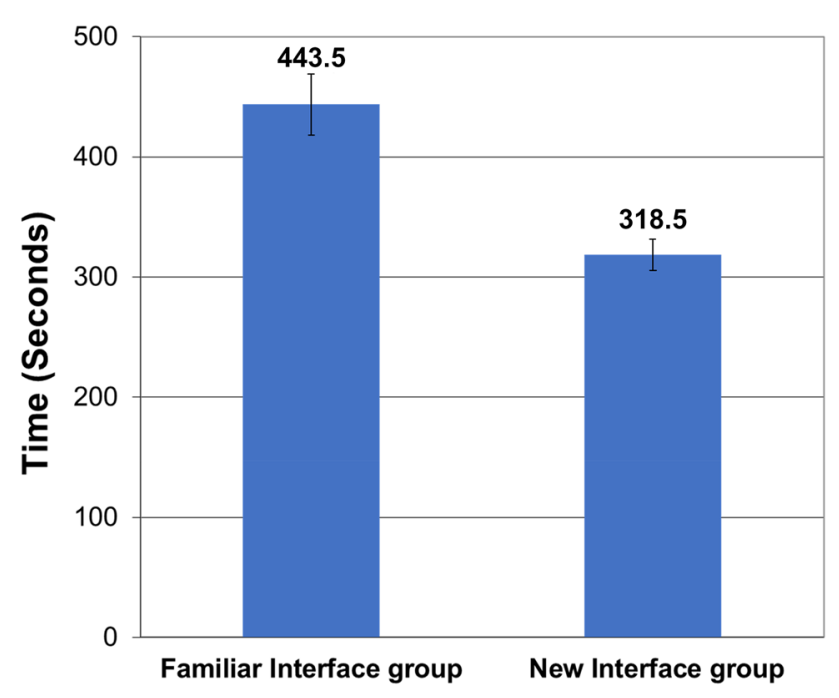

Fig. 7 Total performance time in the transfer stage (mean and standard error bars)

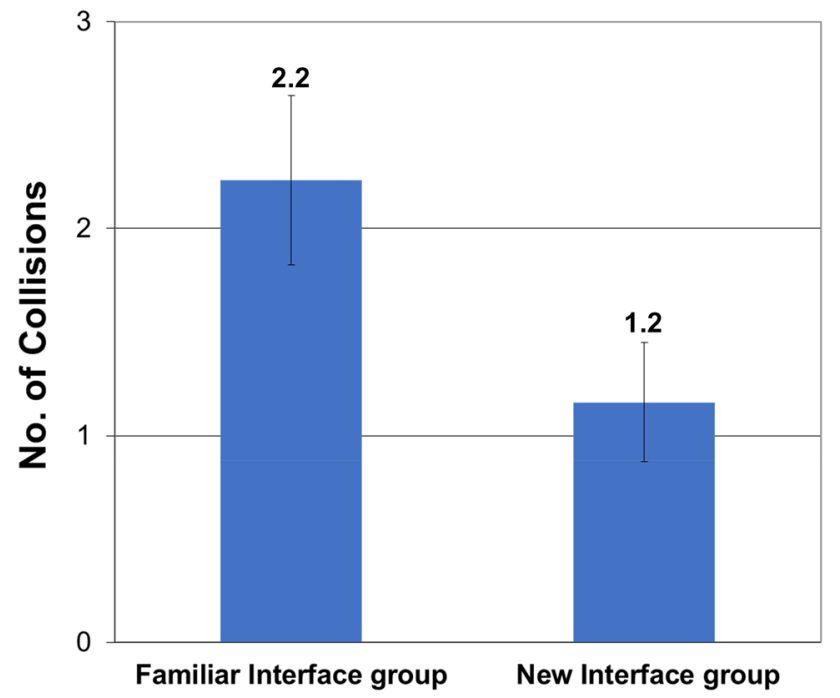

Fig. 8 Total number of collisions (mean and standard error bars)

Some researchers even argue that all of us are, in a sense, cyborgs, merged with technology extenders $[7,10-13,19]$ Hence, the findings regarding the assistive devices' interfaces might be applicable to many of our extender systems that could be perceived as inherent parts of the human body. This, however, is a subject for future research.

The present study's limitation is a lack of a tighter connection to the actual systems we simulated-wheelchairs and carrying platforms. Future studies should use the realworld system as a test bed, and not just a computer simulation, with actual wheelchair users. In addition, generalization of the results for more cases, interfaces and systems is clearly needed.

\section{SN Applied Sciences}

Funding This research was supported in part by the Council for Higher Education Foundation, Israel.

\section{Declarations}

Conflict of interest The authors confirm that they have no conflict of interests.

Consent for publication An ethics approval was given by ORT Braude College ethics committee.

Ethical approval This research complied with the American Psychological Association Code of Ethics and was approved by the Institutional Ethical Committee at ORT Braude College.

Informed consent Informed consent was obtained from each participant.

Open Access This article is licensed under a Creative Commons Attribution 4.0 International License, which permits use, sharing, adaptation, distribution and reproduction in any medium or format, as long as you give appropriate credit to the original author(s) and the source, provide a link to the Creative Commons licence, and indicate if changes were made. The images or other third party material in this article are included in the article's Creative Commons licence, unless indicated otherwise in a credit line to the material. If material is not included in the article's Creative Commons licence and your intended use is not permitted by statutory regulation or exceeds the permitted use, you will need to obtain permission directly from the copyright holder. To view a copy of this licence, visit http://creativecommons. org/licenses/by/4.0/.

\section{References}

1. Aromaa S, Väänänen K (2016) Suitability of virtual prototypes to support human factors/ergonomics evaluation during the design. Appl Ergon 56:11-18. https://doi.org/10.1016/j.apergo. 2016.02.015

2. Baldwin TT, Ford JK (1988) Transfer of training: a review and directions for future research. Pers Psychol 41(1):63-105. https:// doi.org/10.1111/j.1744-6570.1988.tb00632.x

3. Bösser T (1987) Learning in man-computer interaction: a review of the literature. Springer, New York. https://doi.org/10.1007/ 978-3-642-83233-8

4. Carvalko J (2012) The techno-human shell: a jump in the evolutionary gap. Sunbury Press, Pennsylvania

5. Chapanis A (1996) Human factors in systems engineering. Wiley, New Jersey

6. Clynes Manfred E, Kline NS (1960) Cyborgs and space. Astronaut 26-27:74-76

7. De Mul J (2010) Cyberspace odyssey: towards a virtual ontology and anthropology (trans: Dutch). Cambridge Scholars Publishing (originally published 2002)

8. Gentner D, Stevens AL (1983) Mental models. Psychology Press, Hove. https://doi.org/10.4324/9781315802725

9. Hancock PA, Vincenzi DA, Wise JA, Mouloua M (eds) (2008) Human factors in simulation and training. CRC Press, Florida. https://doi.org/10.1201/9781420072846

10. Haraway D (2006) A cyborg manifesto: science, technology, and socialist-feminism in the late 20th century. In: Weiss J, Nolan J, Hunsinger J, Trifonas P (eds) The 
international handbook of virtual learning environments. Springer, Dordrecht, pp 117-158. https://doi.org/10.1007/ 978-1-4020-3803-7_4

11. Hayles NK (2000) How we became posthuman: virtual bodies in cybernetics, literature, and informatics. University of Chicago Press, Chicago. https://doi.org/10.7208/chicago/97802 26321394.001.0001

12. Ihde D (1990) Technology and the lifeword. Indiana University Press, Bloomington, IN

13. Irrgang B (2005) Posthumanes menschsein?: künstliche Intelligenz, cyberspace, roboter, cyborgs und designer-menschen: anthropologie des künstlichen menschen im 21. Franz Steiner Verlag, Jahrhundert

14. Johnson-Laird PN (1983) Mental models: towards a cognitive science of language, inference, and consciousness (No 6). Harvard University Press, Cambridge, MA

15. Kazerooni H (1993) Extender: a case study for human-robot interaction via transfer of power and information signals. In: Proceedings of 1993 2nd IEEE International workshop on robot and human communication. IEEE, pp 10-20. doi:https:// doi.org/10.1109/ROMAN.1993.367756

16. Kazerooni H (1998) Human power extender: an example of human-machine interaction via the transfer of power and information signals. In: AMC'98-Coimbra. 1998 5th International workshop on advanced motion control. Proceedings (Cat. No. 98TH8354). IEEE, pp 565-572)

17. Kieras DE, Bovair $S$ (1984) The role of a mental model in learning to operate a device. Cogn Sci 8(3):255-273. https://doi. org/10.1207/s15516709cog0803_3

18. Kim CS, Lee D, Chung MK (2012) Effects of ramp slope on usability when a wheelchair is propelled by attendant. Proceedings of the human factors and ergonomics society annual meeting, vol 56. SAGE Publications, Los Angeles, pp 629-633. https://doi.org/10.1177/1071181312561131

19. Latour B (2012) We have never been modern. Harvard University Press, Cambridge, MA

20. Lavrov E, Pasko N, Tolbatov A, Barchenko N (2017) Development of adaptation technologies to man-operator in distributed E-learning systems. In: 2017 2nd International conference on advanced information and communication technologies (AICT). IEEE, pp 88-91. doi:https://doi.org/10. 1109/AIACT.2017.8020072

21. Mann WC, Hurren D, Tomita M (1993) Comparison of assistive device use and needs of home-based older persons with different impairments. Am J Occup Ther 47(11):980-987. https:// doi.org/10.5014/ajot.47.11.980
22. Marcheschi S, Salsedo F, Fontana M, Bergamasco M (2011) Body extender: whole body exoskeleton for human power augmentation. In: 2011 IEEE international conference on robotics and automation. IEEE, pp 611-616.) doi:https://doi. org/10.1109/ICRA.2011.5980132

23. McGregor F, Cooper S, Price K, Veillette O, Yousefian S (2018) How is someone's identity as a person affected by the fact that they are a full-time wheelchair user? Am J Occup Ther 72(4_Supplement_1):7211510199p1-7211510199p1. https:// doi.org/10.5014/ajot.2018.72S1-P06033

24. McNeil S (2015) Visualizing mental models: understanding cognitive change to support teaching and learning of multimedia design and development. Educ Technol Res Dev 63(1):73-96. https://doi.org/10.1007/s11423-014-9354-5

25. Norman DA (1983) Some observations on mental models. In: Gentner D, Stevens AL (eds) Mental models. Psychology Press, UK, pp 7-14. https://doi.org/10.4324/9781315802725

26. Ouertani HC, Alhudhud G (2019) Optimizing e-learning cognitive ergonomics based on structural analysis of dynamic responses. Int J Emerg Technol Learn 14(10):150-160. https:// doi.org/10.3991/ijet.v14i10.10134

27. Peruzzini M, Carassai S, Pellicciari M, Andrisano AO (2017) Human-centred design of ergonomic workstations on interactive digital mock-ups. In: Eynard B, Nigrelli V, Oliveri SM, PerisFajarnes G, Rizzuti S (eds) Advances on mechanics, design engineering and manufacturing. Springer, Cham, pp 1187-1195. https://doi.org/10.1007/978-3-319-45781-9_119

28. Schnieders TM, Stone RT (2017) Current work in the humanmachine interface for ergonomic intervention with exoskeletons. Int J Robot Appl Technol 5(1):1-19. https://doi.org/10. 4018/IJRAT.2017010101

29. Weiss A, Avigad G, Ben-Hanan, U (2014) Enhancing wheelchair mobility through dynamics mimicking. In: Proceedings of the 3rd international conference mechanical engineering and mechatronics, Prague, Czech Republic

30. Zhou X, Shen W (2016) Research on interactive device ergonomics designed for elderly users in the human-computer interaction. Int J Smart Home 10(2):49-62. https://doi.org/10.14257/ ijsh.2016.10.2.06

Publisher's Note Springer Nature remains neutral with regard to jurisdictional claims in published maps and institutional affiliations. 